\title{
Nickel-Chromium Electrode as a Detector in Flow-Injection Amperometry: Determination of Glycerol
}

\author{
Ivanildo Luiz de Mattos, Denise Melo and Elias Ayres Guidetti ZaGatTo ${ }^{\dagger}$ \\ Centro de Energia Nuclear na Agricultura, Universidade de São Paulo, \\ P.O. Box 96, Piracicaba-SP 13400-970, Brazil
}

\begin{abstract}
A flow-injection amperometric method for glycerol determination in samples relevant to the industrial production of soaps, detergents and such is presented. A nickel-chromium alloy micro-cylindric electrode was used as the electrochemical detector, which after a pretreatment exhibited good repeatability and stability. The method involved glycerol oxidation by an inactive $\mathrm{Ni}(\mathrm{OH})_{2}$ surface film to a $\mathrm{Ni}(\mathrm{III})$ layer, usually described as $\mathrm{NiOOH}$ (formed in the range from 0.40 to $0.50 \mathrm{~V}$ vs. $\mathrm{Ag} / \mathrm{AgCl})$, and reduction back to the starting hydroxide. The influence of sodium hydroxide $\left(0.1-1.0 \mathrm{~mol} \mathrm{l}^{-1}\right)$ and potassium chloride $\left(0.5-3.0 \mathrm{~mol}^{-1}\right)$ concentrations and sample-injected volume $(10-100 \mathrm{ml})$ on the linear dynamic range, stability and response time of the electrode were evaluated. The proposed system handles about 60 samples per hour and is very stable and suitable for industrial control. Results within 20 and $80 \%$ (w/v) glycerol are precise (rsd $<2 \%$ ) and in agreement with the conventional procedures.
\end{abstract}

Keywords Glycerol, nickel-chromium alloy, cyclic voltammetry, flow-injection, amperometry

Almost all of the applications of trihydric alcohols are included in the more than 150 uses of glycerol e.g., humectant, solvent, plasticizer, component of pharmaceuticals, and as a derivative employed in plastics, coatings, explosives and foods. ${ }^{1}$ Moreover, glycerol is one of the most important compounds to be monitored in a sugar-fermentation plant in order to improve the quality control of the process. ${ }^{2}$ In the soap industry, monitoring of the glycerol concentration in lixivia and such is relevant in view of the related economical aspects.

Advanced analytical characteristics are required for industrial control, and an increasing number on the applications of chemically modified electrodes as amperometric detectors in flow systems have been reported. ${ }^{3-9}$ These include electrodes based on copper, cobalt and nickel for the electrocatalytic oxidation of carbohydrates in an alkaline solution at low potential.

Nickel electrodes exhibit catalytic activity in the oxidation of a wide variety of organic compounds in alkaline solutions. The $\mathrm{Ni}$ (III) species is generated on the electrode surface at potentials in the region of 0.4 to 0.5 $\mathrm{V} v$ s. $\mathrm{Ag} / \mathrm{AgCl}$. The reactions are:3,7

$$
\begin{aligned}
& \mathrm{Ni}+2 \mathrm{OH}^{-} \leftrightarrow \mathrm{Ni}(\mathrm{OH})_{2}+2 \mathrm{e}^{-} \\
& \mathrm{Ni}(\mathrm{OH})_{2}+\mathrm{OH}^{-} \leftrightarrow \mathrm{NiOOH}+\mathrm{e}^{-} \\
& \mathrm{NiOOH}+\text { analyte } \rightarrow \mathrm{Ni}(\mathrm{OH})_{2}+\text { radical } \rightarrow \text { product }+\mathrm{e}^{-}
\end{aligned}
$$

Glycerol can be determinated by monitoring the $\mathrm{Ni}(\mathrm{II})$ and re-oxidizing this species by applying a suit-

$\doteqdot$ To whom correspondence should be addressed. able potential. Despite the versatility, simplicity and suitability of the nickel-chromium alloy as an amperometric detector, and the relevance of glycerol monitoring for the industrial production of soaps, detergents and such, the use of Ni-Cr alloy electrodes for this determination had not yet been reported.

The main purpose of the present work was thus to develop a simple, fast and low-cost flow-injection procedure for glycerol determination in lixivia. Glycerol electrocatalytic oxidation in an alkaline medium at low potential was exploited. For this task, a Ni-Cr wire was used as an electrochemical detector, and its chemical composition and electrochemical characteristics were investigated.

\section{Experimental}

\section{Apparatus}

The electrochemical system comprised a MQPG-01 Microquimica computerized potenciostat (Florianópolis-SC, Brazil) equipped with $\mathrm{Ag} / \mathrm{AgCl}$ (3 mol $1^{-1} \mathrm{KCl}$ ) reference and platinum auxiliary electrodes (spiral, $0.2 \times 100 \mathrm{~mm}$ ) sealed in alkaline glass. The working electrode was made of Ni-Cr ( $c a$. 80:20 $\mathrm{w} / \mathrm{w}$ ) by sealing the metal wire (o.d. $1.0 \mathrm{~mm}$ ) in a glass tube so as to leave about $1-\mathrm{cm}$ length exposed (microcylinder). Unless otherwise indicated, the potential scan rate was $100 \mathrm{mV} \mathrm{s}^{-1}$. Flow-injection experiments were carried out in a system with an IPC-8 Ismatec peristaltic pump (Zürich, Switzerland) furnished with Tygon pumping tubes, a home-made injector ${ }^{10}$ and 0.8 


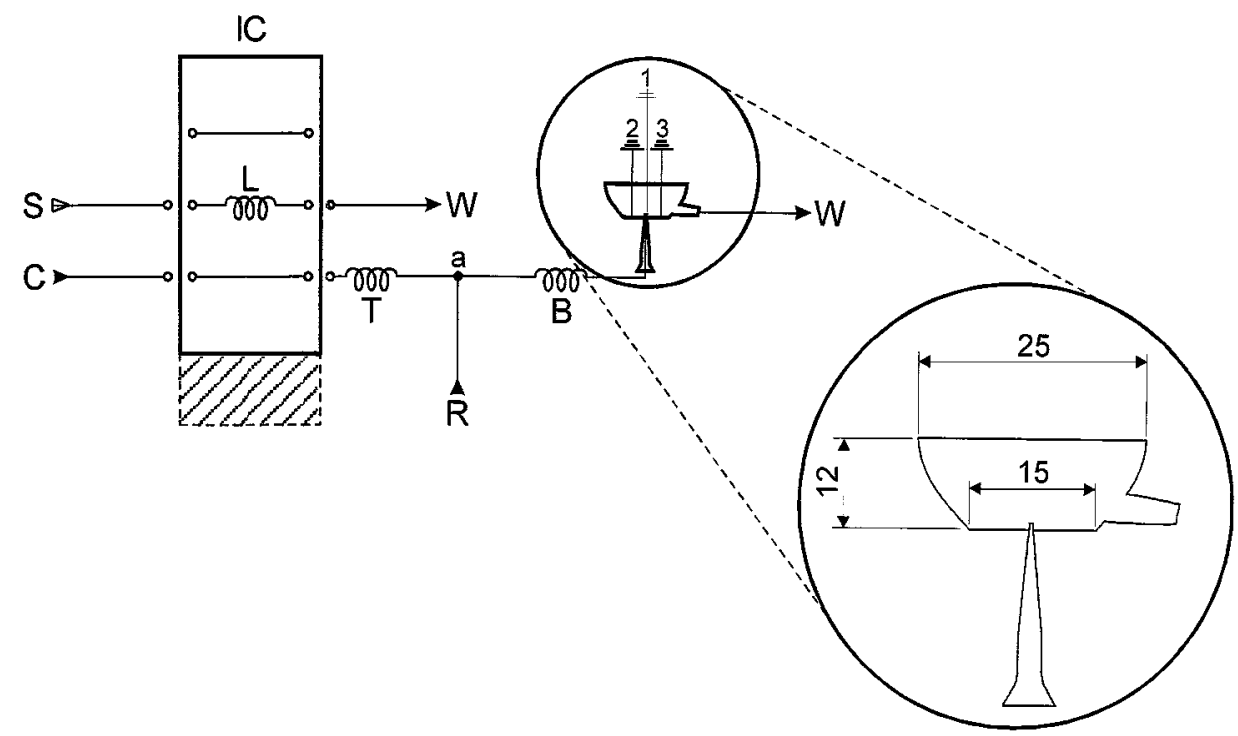

Fig. 1 Flow diagram. S, sample; L, sampling loop; IC, injector; C, carrier stream; R, reagent (combined) stream; T, transmission line; a, confluence point; B, coiled reactor; W, waste; Window the glass electrochemical cell; 1, 2 and 3, Ni-Cr alloy, platinum auxiliary and $\mathrm{Ag} / \mathrm{AgCl}\left(3.0 \mathrm{~mol} \mathrm{l}^{-1} \mathrm{KCl}\right)$ reference electrodes. Black arrows indicate sites where the peristaltic pump is applied. Numbers are dimensions, in $\mathrm{mm}$.

$\mathrm{mm}$ i.d. polyethylene tubing. The electrochemical cell is depicted in Fig. 1.

\section{Reagents, standards and samples}

All solutions were prepared with distilled water and pro analisi substances.

Reagent R (Fig. 1) was a 0.5 mol $\mathrm{l}^{-1}$ sodium hydroxide plus $2.0 \mathrm{~mol} \mathrm{l}^{-1}$ sodium chloride stored in an amber bottle. Working standard solutions within 0.10 and $1.00 \%(\mathrm{w} / \mathrm{v})$ glycerol were freshly prepared by dilution of the concentrated glycerol stock $(99.7 \%(\mathrm{w} / \mathrm{w}))$ with water. Samples (lixivia from Gessy Lever Co, Valinhos SP, Brazil) were collected in 250-ml bottles. The initial dilution was accomplished by accurately weighing $5 \mathrm{~g}$ of the solution and mixing with $500 \mathrm{ml}$ of water. Whenever needed, further manual water dilution was performed immediately before sample injection into the flow system. The Ni-Cr alloy was purchased in a local shop. It was pretreated according to Stitz and Burchberger: ${ }^{11}$ the potential was fixed at $3.0 \mathrm{~V}$ during 5 min with a $0.1 \mathrm{~mol} \mathrm{l}^{-1}$ sodium hydroxide solution at $70^{\circ} \mathrm{C}$.

For the analysis of the nickel-chromium alloy, the wire (about $50 \mathrm{mg}$ ) was dissolved in $10 \mathrm{ml}$ of acqua regia and the volume filled to $100 \mathrm{ml}$ with water. For the determination of the minor elements by ICP-AES ${ }^{12}$, standard solutions (1000 $\mathrm{mg} \mathrm{l}^{-1}$ in $\mathrm{Ni}$ and $\mathrm{Cr}$ ) were used for corrections. For $\mathrm{Ni}$ and $\mathrm{Cr}$ determination, the digests underwent further 1:100 dilution in $0.014 \mathrm{~mol} \mathrm{l}^{-1}$ $\mathrm{HNO}_{3}$.

\section{The flow injection system}

The sample was injected into the flow system (Fig. 1) by means of a $5-\mathrm{cm}(c a .25 \mathrm{ml})$ sampling loop and pushed by its carrier stream $\left(0.1 \mathrm{~mol} \mathrm{l}^{-1} \mathrm{NaOH}\right.$ at 1.2 $\mathrm{ml} \mathrm{min}{ }^{-1}$ ) towards the detector with a fixed potential $(0.5 \mathrm{~V} v s . \mathrm{Ag} / \mathrm{AgCl})$. At the confluent point (a), located $5 \mathrm{~cm}$ from the injection port, the sample zone received the reagent $\left(0.5 \mathrm{~mol} \mathrm{l}^{-1} \mathrm{NaOH}\right.$ plus $2.0 \mathrm{~mol} \mathrm{l}^{-1} \mathrm{KCl}$ at $1.2 \mathrm{ml} \mathrm{min}{ }^{-1}$ ) flowing through the $25-\mathrm{cm}$ coiled reactor. Passage of the processed sample through the electrochemical cell produced a transient anodic current proportional to the glycerol content in the sample.

After defining the hydrodynamic conditions, the system shown in Fig. 1 was applied to analyses of lixivia collected from different positions of the plant production. Precision was expressed as the relative standard deviation estimated after eleven successive analyses of typical samples (about $40 \%(\mathrm{w} / \mathrm{v})$ glycerol), and the accuracy was assessed by running samples already analyzed by Gessy Lever Co.

\section{Results and Discussion}

The electrochemical behavior of the alloy electrode was similar to that exhibited by the pure nickel electrode. For the interval of +0.3 to $+0.7 \mathrm{~V} \mathrm{vs.} \mathrm{Ag} / \mathrm{AgCl}$, voltammograms obtained with a $\mathrm{Ni}-\mathrm{Cr}$ alloy electrode in the absence of the analyte consisted of a pair of anodic and cathodic waves at +0.54 and $+0.47 \mathrm{~V}$ vs. $\mathrm{Ag} / \mathrm{AgCl}$. These values, at $0.1 \mathrm{~mol} \mathrm{l}^{-1} \mathrm{NaOH}$ solution, are near to those reported for the nickel electrode., $4,13,14$ This feature demonstrates that an alloy with $c a .80 \% \mathrm{Ni}$ (Table 1) is appropriate for use as an amperometric detector. In this way, addition of chromium or other metals stabilized the nickel electrode. It should be noted that Marioli et al. ${ }^{7}$ reported that in addition to 


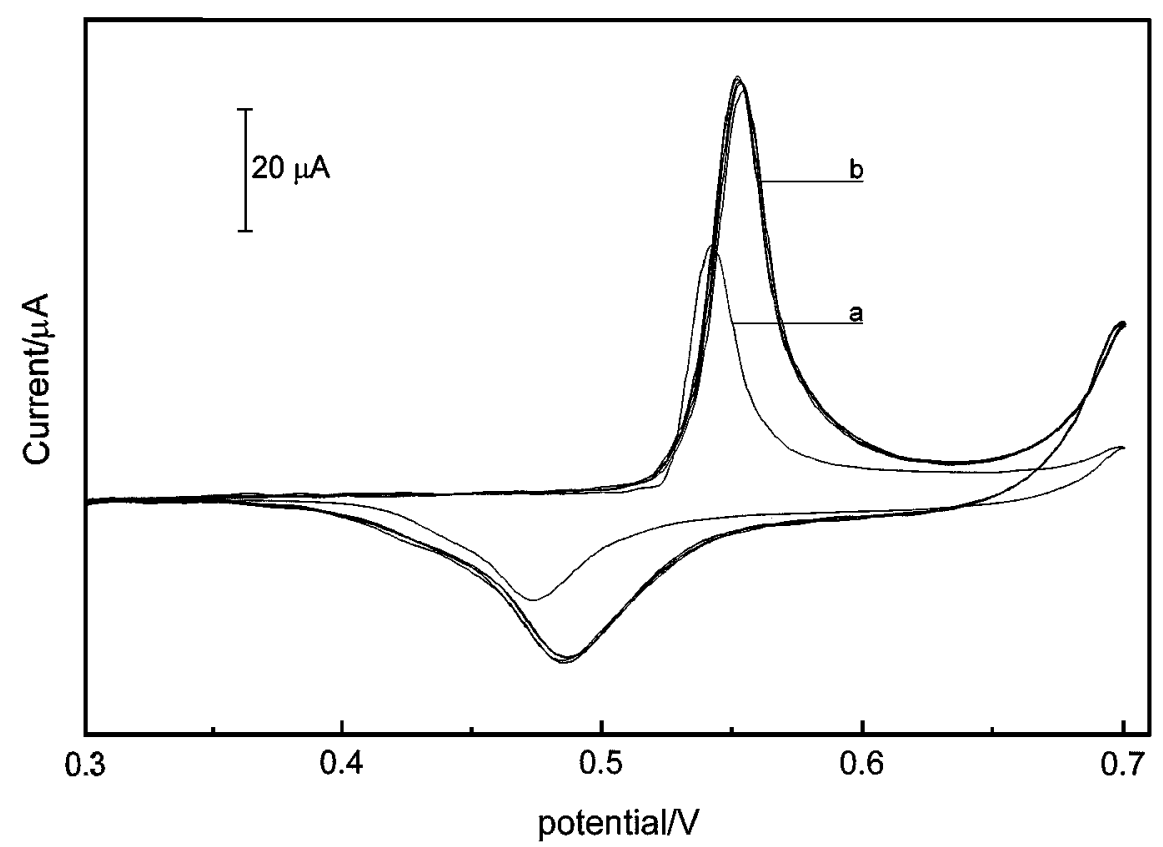

Fig. 2 Cyclic voltammograms obtained before (a) and after (b) pretreatment. Scan rate $=100 \mathrm{mV} \mathrm{s}^{-1}$.

Table 1 Chemical analysis of the nickel-chromium alloy

\begin{tabular}{ccccc}
\hline Sample & $\% \mathrm{Ni}$ & $\% \mathrm{Cr}$ & $\% \mathrm{Fe}$ & $\% \mathrm{Mn}$ \\
\hline 01 & $78.76 \pm 0.20$ & $21.35 \pm 0.02$ & $0.57 \pm 0.01$ & $0.02 \pm 0.01$ \\
02 & $79.87 \pm 0.40$ & $22.54 \pm 0.54$ & $0.59 \pm 0.01$ & $0.02 \pm 0.01$
\end{tabular}

Results $(\%(\mathrm{w} / \mathrm{v}))$ are presented with estimated standard deviations $(n=3)$.

increased stability, the nickel alloys retained the electrochemical characteristics of the base metal. In view of these aspects and considering that alloys are usually cheaper than metals, the use of an alloy electrode is an important contribution for increasing the versatility of electrochemical techniques.

Figure 2 shows the behavior of the alloy before and after a pretreatment with a $0.1 \mathrm{~mol} \mathrm{l}^{-1} \mathrm{NaOH}$ solution at $70^{\circ} \mathrm{C}$. For this experiment, the electrode was prepared ten days earlier. Both the anodic and cathodic waves of the $\mathrm{Ni}(\mathrm{II}) / \mathrm{Ni}(\mathrm{III})$ pair after the treatment were slightly displaced towards more positive potentials $(+0.55$ and $+0.49 \mathrm{mV} v s . \mathrm{Ag} / \mathrm{AgCl})$. In this situation, an increase (ca.65\%) in the anodic current (from 42.4 to $70 \mu \mathrm{A}$ ) was noted. In an alkaline solution, active $\mathrm{NiOOH}$ was formed around $+0.5 \mathrm{~V} v s$. $\mathrm{Ag} / \mathrm{AgCl}$, where the $\mathrm{Ni}(\mathrm{III})$ layer acted as a strong oxidant. The proportionality between the current and the glycerol concentration arose form nickel re-oxidation (Fig. 3). The addition of any of the tested compounds produced an increase in the anodic and a decrease in the cathodic component of the nickel couple. By comparing Figs. 2 and 3, one can note that in spite of a lessening of the current background (signal in the absence of analyte), the perform- ance of the electrode was satisfactory $(r=0.9995, n=5)$. This experiment also demonstrated the life-time and stability of the electrode response. Details of the alloy pretreatment are given elsewhere. ${ }^{11}$

An alkaline medium is needed to produce high valent oxides of metals for the oxidation of organic molecules $^{13}$, and the $\mathrm{Ni}(\mathrm{II}) / \mathrm{Ni}(\mathrm{III})$ peaks disappear in solutions with $\mathrm{pH}<4.5$. In this way, the influence of the sodium hydroxide concentration was verified within 0.05 and $2.0 \mathrm{~mol} \mathrm{l}^{-1}$ in the electrode pretreatment $\left(70^{\circ} \mathrm{C}\right.$ and $3.0 \mathrm{~V} \mathrm{vs.} \mathrm{Ag} / \mathrm{AgCl}$ during $5 \mathrm{~min}$ ). When this concentration was increased beyond $0.1 \mathrm{~mol} \mathrm{l}^{-1}$, a shift towards high potentials was observed (condition of higher vulnerability to foreign species), and the system stability deteriorated (rsd $>5 \%$ for typical samples, $n=11$ ). For concentrations lower than $0.1 \mathrm{~mol} \mathrm{l}^{-1}$, no macroscopic black oxide film on the electrode surface was observed. This result confirmed earlier work. ${ }^{11}$ Then, the sodium hydroxide concentration was defined as $0.1 \mathrm{~mol} \mathrm{l}^{-1}$ in order to fix the potential at a low value.

\section{Flow system}

Optimization of the variables involved in the system design was performed by the univariate method. Table 2 gives the ranges over which each variable was studied and the selected value. For these investigations, the flow system shown in Fig. 2 was employed with $0.00-1.00 \%(\mathrm{w} / \mathrm{v})$ glycerol standard solutions. The potential of anodic peak was fixed as $0.5 \mathrm{~V} v s$. $\mathrm{Ag} / \mathrm{AgCl}$. Increasing the injected volume $(10-50 \mu \mathrm{l})$ led to a favorable effect on the analytical signal. Beyond $50 \mu 1$ the signal did not increase, probably owing to saturation of the electrode. In addition, pronounced losses in the linearity and sampling rate were 


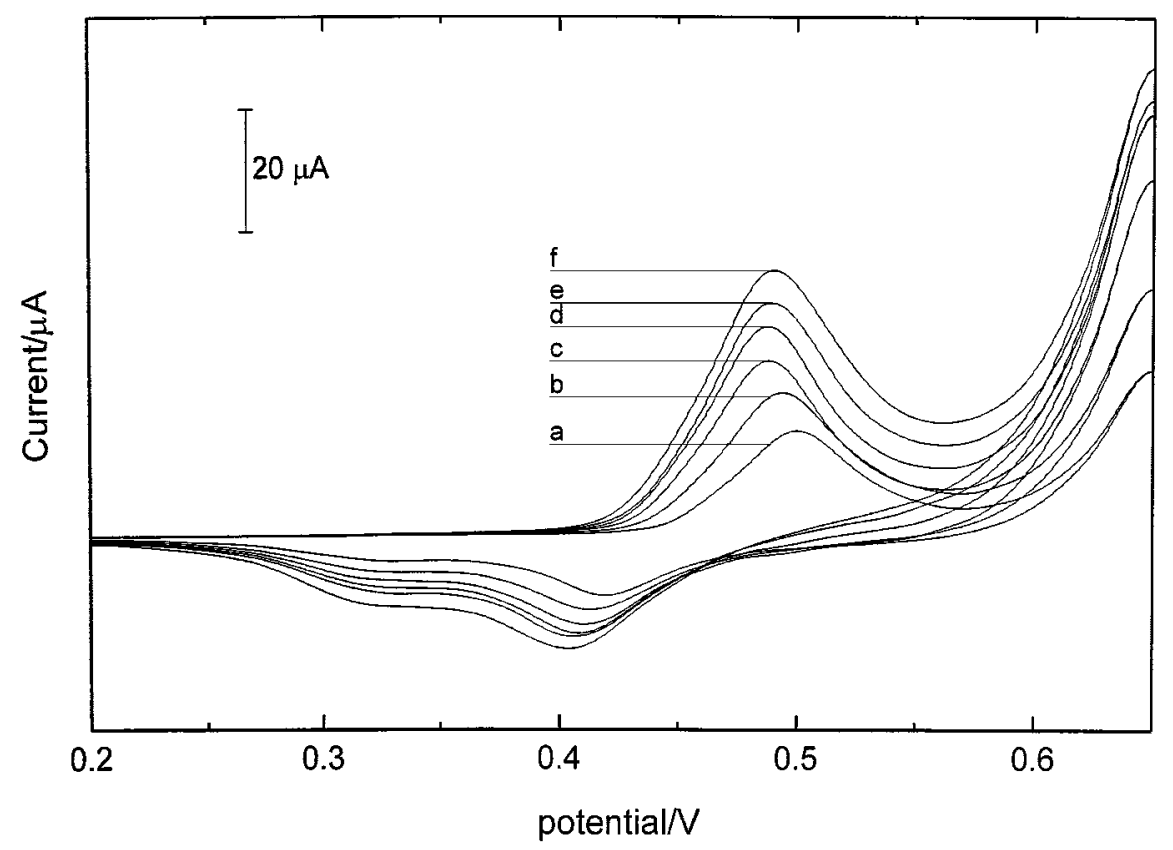

Fig. 3 Cyclic voltammograms for 0.00 (a), 0.10 (b), 0.20 (c), 0.30 (d), 0.40 (e) and $0.50(\mathrm{f}) \%(\mathrm{w} / \mathrm{v})$ glycerol in $0.1 \mathrm{~mol}^{-1}$ sodium hydroxide.

Table 2 Optimization of the variables

\begin{tabular}{lcc}
\hline & Studied range & Selected value \\
\hline Flow rate $/ \mathrm{ml} \mathrm{min}^{-1}$ & $0.5-2.5$ & 1.2 \\
Loop length $/ \mathrm{cm}$ & $25-100$ & 25 \\
Injected volume $/ \mu \mathrm{l}$ & $10-100$ & 20 \\
$\mathrm{NaOH} / \mathrm{mol} \mathrm{l}^{-1}$ & $0.05-2.0$ & 0.1 \\
$\mathrm{NaOH} / \mathrm{mol} \mathrm{l}^{-1}+\mathrm{KCl} / \mathrm{mol} \mathrm{l}^{-1}$ & $0.1-1.0 / 0.5-3.0$ & $0.5 / 2.0$ \\
\hline
\end{tabular}

observed. For $20 \mu$ l, high correlations between the current and the concentration, combined with a suitable sampling frequency were attained.

The linearity of the analytical equation was also investigated by varying the scan rate up to $200 \mathrm{mV} \mathrm{s}^{-1}$. Within 10 and $200 \mathrm{mV} \mathrm{s}^{-1}$, several analytical curves based on $0.10-0.80 \%(\mathrm{w} / \mathrm{v})$ glycerol standard solutions were obtained. At $100 \mathrm{mV} \mathrm{s}^{-1}$, the correlation between the concentration and the anodic current was highest.

The influence of the flow rate on the analytical signal was investigated by varying it from 0.5 to $2.5 \mathrm{ml} \mathrm{min}^{-1}$. For flow rates $<0.8 \mathrm{ml} \mathrm{min}^{-1}$, the recorded peak heights were increased, but the strategy resulted in an unacceptable low sampling rate. For values higher than 1.5 $\mathrm{ml} \mathrm{min}{ }^{-1}$, in spite of the high sampling frequency, the system stability deteriorated ( $\mathrm{rsd}>7 \%, n=11)$. The flow rate was then fixed at $1.2 \mathrm{ml} \mathrm{min}^{-1}$.

The effect of the reagent concentration was studied by varying both the sodium hydroxide $(0.1-1.0 \mathrm{~mol}$ $\left.\mathrm{l}^{-1}\right)$ and potassium chloride $\left(0.5-3.0 \mathrm{~mol} \mathrm{l}^{-1}\right)$ concentrations. The concentration of sodium hydroxide was fixed at $0.5 \mathrm{~mol} \mathrm{l}^{-1}$ in order to avoid any pronounced variations in this concentration into the cell due to the nature of the injected sample $(1.0-5.0 \%(\mathrm{w} / \mathrm{v})$ in sodi- um hydroxide). Potassium chloride was always in large excess relative to sodium hydroxide; as for concentrations lower than $1.0 \mathrm{~mol} \mathrm{l}^{-1}$ (or even without $\mathrm{KCl}$ ), slight variations in the recorded peaks, usually $<10 \%$ were noted. Above $2.0 \mathrm{~mol} \mathrm{l}^{-1}$, the system yielded more reproducible results. Then, $0.5 \mathrm{~mol} \mathrm{l}^{-1}$ sodium hydroxide plus $2.0 \mathrm{~mol} \mathrm{l}^{-1}$ potassium chloride was selected as the reagent $R_{1}$.

The electrocatalytic oxidation in an alkaline medium at low potential is vulnerable to interferants. $\mathrm{Ni}(\mathrm{III})$ acts as a strong oxidant and reacts with some chemical species. To minimize this drawback, it is necessary to separate these components before analysis. In the present work, because the sample was basically composed of sodium hydroxide $(0.05-0.9 \%(\mathrm{w} / \mathrm{v}))$ and sodium chloride $(10-15 \%(\mathrm{w} / \mathrm{v}))$, there was no problem related to this aspect. On the other hand, a beneficial effect was observed by adding sodium hydroxide to $\mathrm{R}_{1}$. The only preoccupation was to keep the sodium hydroxide concentration as constant as possible.

\section{Applications}

After being dimensioned, the flow-injection system was applied to an analysis of lixivia (Fig. 4). The longterm stability of the system was evaluated by injecting different samples during 8-h working periods. The system robustness was emphasized after these experiments, because no significant variation in the baseline was noted. Calibration equations were attained by least-squares regression: $y=0.66+127.85 x-59.39 x^{2}$, where $y$ is the anodic current in $\mu \mathrm{A}$ and $x$ is the concentration of glycerol in $\%(\mathrm{w} / \mathrm{v})$. For $n=5$, the typical regression coefficient was 0.9994 . Using the proposed system, about 60 samples can be run per hour. The 


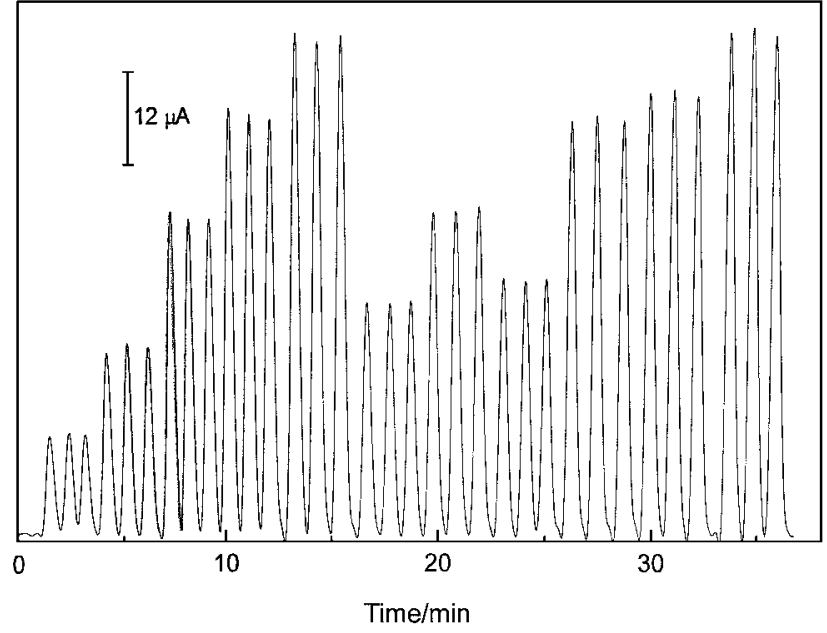

Fig. 4 Recorder output of a routine run. From left, triplicate measurements of five glycerol standard solutions $(0.10,0.20$, $0.40,0.60$ and $0.80 \%(\mathrm{w} / \mathrm{v}))$ : sample 1 , standard $0.40 \%(\mathrm{w} / \mathrm{v})$; sample 2, standard $0.60 \%(\mathrm{w} / \mathrm{v})$; sample 3 , standard $0.80 \%(\mathrm{w} / \mathrm{v})$.

sampling rate can be improved by reducing the mean available time for glycerol oxidation. Considering the low cost of the proposed system (1 meter of nickelchromium alloy costs about US\$0.20) and its versatility, one may conclude that it is suitable for large-scale analysis and/or for quality control. The detection limit was estimated to be $0.01 \%(\mathrm{w} / \mathrm{v})$ glycerol. For a typical lixivia sample with a glycerol content of about $40 \%(\mathrm{w} / \mathrm{v})$, the relative standard deviation of thirteen results was estimated as $1.85 \%$. The accuracy was assessed by running three already analyzed samples ${ }^{15}$, and only slight differences in results obtained by the different methods were found (Table 3 ).

The nickel-chromium wire demonstrated potentialities to be used as a working electrode. It presented a performance very similar to the nickel electrode, and satisfactory results. The facilities of its pretreatment and the low cost are other advantageous characteristics of the electrode.

Simplicity of the set-up for its implementation, good selectivity and stability, and a high sampling frequency make the system exploiting the nickel-chromium alloy electrode an efficient tool to perform automated analysis in a simple, fast and robust way. It is suitable for routine determinations and on-line monitoring of glycerol in real plants.

The proposed method can be well-adjusted for other kind of samples, representing an alternative to the chromatographic analysis usually required for industrial control quality.
Table 3 Concentrations of glycerol in $\%(\mathrm{w} / \mathrm{v})$ as determined in lixivia samples by the proposed (FIA) and reference methods (ref.15)

\begin{tabular}{ccc}
\hline Sample $^{\mathrm{a}}$ & FIA & AOAC \\
\hline 1 & 26.5 & 26.1 \\
2 & 27.6 & 27.7 \\
3 & 62.3 & 62.5 \\
\hline
\end{tabular}

a. Dilution: 1/100(w/v).

This work was supported by FAPESP (Projects 96/09722-1 and 97/3305-2). Gessy Lever Co., Valinhos SP (Brazil) is thanked for supplying the analyzed samples.

\section{References}

1. J. A. Monick, "Alcohols-Their chemistry, properties and manufacture", ed. Reinhold Book Corporation, New York, 1968.

2. J. M. Paturau, "By-products of the cane sugar industry-an introduction to their industrial utilization", ed. Elsevier, Amsterdam, 1980.

3. B. S. Hui and C. O. Huber, Anal. Chim. Acta, 134, 211 (1982).

4. P. Luo, F. Zhang and R. P. Baldwin, Anal. Chim. Acta, 244, 169 (1991).

5. L. Gorton, E. Csöregi, E. Dominguez, J. Emnéus, G. Jöhnsson-Petersson, G. Marko-Varga and B. Persson, Anal. Chim. Acta, 250, 203 (1991).

6. C. M. A. Brett and A. M. O. Brett, "Electrochemistryprinciples, methods and applications", Oxford University Press Inc., New York, 1993.

7. J. M. Marioli, P. Luo and T. Kuwana, Anal. Chim. Acta, 282, 571 (1993).

8. J. Wang, “Analytical electrochemistry”, VHC, New York, 1994.

9. C. H. Cai, K. H. Xue, Y. M. Zhou and H. Yang, Talanta, 44, 339 (1997).

10. F. J. Krug, E. A. G. Zagatto and H. Bergamin $\mathrm{F}^{\circ}$, Anal. Chim. Acta, 179, 103 (1986).

11. A. Stitz and W. Buchberger, Fresenius' J. Anal. Chem., 339, 55 (1991)

12. A. O. Jacintho, B. R. Figueiredo, B. F. Reis, E. A. G. Zagatto, F. J. Krug, M. F. R. Giné, M. C. U. Araújo, N. M. Pereira and R. E. Bruns, "Análises químicas de rochas por ICP-AES”, ed. B. R. Figueiredo, Unicamp, Campinas, Brasil, 1985.

13. I. G. Casella, E. Desimoni and A. M. Salvi, Anal. Chim. Acta, 243, 61 (1991).

14. I. G. Casella, E. Desimoni and T. R. I. Cataldi, Anal. Chim. Acta, 248, 117 (1991).

15. A. O. C. S. "Tentative method", Da 23-56 (amended 1959).

(Received December 21, 1998) (Accepted April 8, 1999) 